\title{
COALITIONAL APPROACHES TO COLLUSIVE AGREEMENTS IN OLIGOPOLY GAMES*
}

\author{
by \\ SERGIO CURRARINI \\ University of Leicester and Universita' di Venezia \\ and \\ MARCO A. MARINI \\ Sapienza Università di Roma and CREI
}

In this paper we review a number of coalitional solution concepts for the analysis of cartel and merger stability in oligopoly. We show that, although so far the industrial organization and the cooperative game theoretic literature have proceeded somehow independently on this topic, the two approaches are highly inter-connected. We show that different assumptions on the behaviour and on the timing of the coalitions of firms yield very different results on the associations of firms which are stable. We conclude by reviewing some recent extensions of the coalitional analysis to oligopolistic markets with heterogeneous firms and incomplete information.

\section{INTRODUCTION}

Since the seminal work by Salant et al. (1983) on merger profitability, there has been a large interest in the stability of collusive agreements between firms in oligopoly, as in the case of cartels, mergers and alliances (e.g. d'Aspremont et al., 1982; Deneckere and Davidson, 1985; Perry and Porter, 1985; d'Aspremont and Gabszewicz, 1986; Donsimoni et al., 1986; Jaquemin and Margareth, 1989; Rajan, 1989; Farrell and Shapiro, 1990; and also Huck et al., 2005a, 2005b for an extensive survey). A relevant number of the initial works on the topic has mainly focused on the conditions under which a collusive agreement within one group of firms can be viewed as stable when the remaining firms in the industry act either as price-takers (d'Aspremont et al., 1982; Donsimoni et al., 1986, among others) or as oligopolistic firms (see Shaffer, 1995). As in the traditional price-leadership

* Manuscript received 27.7.12; final version received 19.2.14.

$\dagger$ The first author acknowledges funding from the Italian Ministry of Education, University and Research and the Italian Ministry of Environment, Land and Sea under the GEMINA project. The second author acknowledges financial support from the Italian Ministry of Education, University and Research under the PRIN project 'Climate changes in the Mediterranean area: scenarios, economic impacts, mitigation and innovation policies'. We wish to thank Francis Bloch, Michael Kopel, Jacquelin Morgan, Maria Luisa Petit, Kevin Roberts, Giorgio Rodano, Francesca Sanna Randaccio, Yair Tauman and an anonymous referee for their helpful comments and discussions on earlier drafts of this paper. 
model (Markham, 1951), in the above literature a group of dominant firms is assumed to behave as one Stackelberg leader, i.e. taking as given the reaction of the remaining firms in the fringe. Since in the absence of synergies the cooperation within a cartel is formally equivalent to the outcome of a horizontal merger, many of the results of the horizontal merger literature also apply to the problem of cartel stability. ${ }^{1}$ However, differently from the cartel literature, most of the works on horizontal mergers examine the profitability of mergers in oligopolistic markets where a group of colluding firms and a fringe of competitors take their strategic decisions simultaneously. ${ }^{2}$

A common feature of both the approaches discussed above is the adoption of a notion of individual stability: for a cartel (or merger) to be stable, no firm of the fringe must have an incentive to enter the cartel (external stability) and no firm of the cartel must have an incentive to exit the cartel (internal stability). Recognizing the fact that this approach '... ignores the possibility that a group of players might jointly make themselves better off by leaving the cartel (Shaked, 1986)', later contributions have, in various ways, attempted to use a notion of coalitional stability to approach the problem (see, for instance, d'Aspremont and Gabszewicz, 1986; Rajan, 1989, Zhao, 1997; Thoron, 1998). The main purpose there is to check whether imputations exist under which a collusive agreement signed by all firms in the industry is stable, i.e. immune to deviations by subcoalitions of firms in the industry. As in the horizontal mergers literature, the stability of an agreement is examined in a context in which a deviating coalition and the remaining firms of the industry act simultaneously. In such a literature, the sequential approach typical of the price-leadership model is, therefore, missing. It may be questioned whether the defection of a group of firms from a cartel and their defective market decisions have to be viewed as happening either before or at the same time as the market decision of the remaining firms. Clearly, some sequential structure would prove useful to describe all those situations in which a coalition of firms can commit to a joint (defective) strategy expecting outside firms to observe the effects of such strategy and to optimally react to it.

The purpose of this paper is to review some recent applications of cooperative games and of coalition formation games to the problem of collusive agreements (e.g. cartels and mergers) in oligopoly. Our aim is to highlight the implications of different game structures and equilibrium con-

${ }^{1}$ This equivalence holds in particular if the firms in the cartel are assumed to sign a binding agreement on their joint prices or quantities.

${ }^{2}$ Other recent works on this topic also looks at the profitability of mergers under nonlinear demand (Cheung, 1992; Faulí-Oller, 1997), strategic delegation in mergers (Gonzalez-Maestre and Lopez-Cunat, 2001; Ziss, 2001), mergers under incomplete information (Amir et al., 2009), mergers and cartels with Stackelberg leaders and followers (Daughety, 1990; Huck et al., 2001; Escrihuela-Villar and Faulí-Oller, 2008). 
cepts for the final configuration of the industry. To examine this question, we first introduce the notion of core of a cooperative $T U$-game and then apply it to check the stability of a merger or a cartel made of all firms in the industry. We show that while the simultaneous approach to cartel formation has led to the notions of gamma-core and delta-core (see, for instance, Chander and Tulkens, 1997, and, more recently, Lardon, 2012), the sequential approach has led to a core notions based on the assumption that deviating coalitions act as Stackelberg leaders in setting their market strategies (see Currarini and Marini, 2003, 2004). We are so able to clarify and extend some classical results on merger stability contained, for instance, in Rajan (1989).

Obviously, the formation of collusive structures which are different from the whole association of firms in the industry represent a concrete option for firms competing in oligopoly. The recent developments in the theory of endogenous coalition formation provides, in this respect, a new set of gametheoretic tools to study this problem (Hart and Kurz, 1983; Bloch, 1995; Ray and Vohra, 1997; Yi, 1997; and also Bloch, 1997, 2002, 2003; Yi, 2003; Marini, 2009, for updated surveys of the literature). In all these works, the formation of competing associations of firms is modelled as a two-stage process: in a first stage players form coalitions, while at the second stage the formed coalitions interact in the resulting market structure. A basic difference among the various models lies on the timing assumed for the coalition formation game, which can be either simultaneous (Hart and Kurz, 1983; Ray and Vohra, 1997; Yi, 1997) or sequential (Bloch, 1995; Ray and Vohra, 1999). Another remarkable difference lies in the timing of the strategic settings used to model second stage market competition.

We therefore focus here specifically on role of timing of the oligopoly game. To this aim we make an attempt to extend the logic of Hamilton and Slutsky's (1990) two-player endogenous timing game to the formation of coalitions of firms. In particular we construct a model in which firms announce the time at which they wish to play the oligopoly game, as well as the coalitions they wish to belong to. We assume that these announcements induce a profile of coalitions according to a unanimity rule: a coalition forms if and only if all its members agree to belong to that coalition, and study the existence of a strong Nash equilibrium of the coalition formation and timing game. Applying this framework of endogenous timing to the oligopoly problem allows us to set in a broader perspective a number of recent results on mergers profitability with Stackelberg leaders and followers (e.g. Daughety, 1990; Huck et al., 2001, 2005a, 2005b).

Finally, in a conclusive section, we review some recent results obtained by the coalitional approach in Cournot oligopoly games in which firms either are heterogeneous (in terms of cost or demand structures) or possess private information either on market conditions or on rival firms.

The paper is organized as follows. The next section introduces a basic quantity oligopoly game that is used as the underlying strategic form game 
throughout the paper. Section 3 is devoted to the formation of the industrywide alliance of firms and, for this reason, it reviews the results obtained applying the notion of core to the analysis of collusive agreements in quantity setting oligopolies. Section 4 considers the stability of partial cartels and mergers and reviews some recent approaches adopted to model the endogenous formation of coalitions of firms, with a special attention to the issue of timing. Section 5 present some recent applications of the coalitional approach to oligopoly games in presence of heterogeneous firms and of incomplete information. Section 6 concludes.

\section{A Quantity Oligopoly Game}

Let the profit function of every firm $i \in N=\{1,2, \ldots, n\}$ be defined as

$$
\pi_{i}\left(y, y_{i}\right)=p(y) y_{i}-C_{i}\left(y_{i}\right)
$$

where $y_{i}$ is the output of each firm, $y=\sum_{i=1}^{n} y_{i}$ the total industry output, $p(y)$ the inverse demand function and $C_{i}\left(y_{i}\right)$ the cost function of every firm. Let also $C_{i}(\cdot)=C_{j}(\cdot)$, for every $i, j$ in $N$. Thus, we can represent the Cournot oligopoly through the following strategic form game, $G=\left(\left\{Y_{i}, \pi_{i}\right\}_{i \in N}\right.$, $\left.\left\{Y_{S}\right\}_{S \subseteq N}\right)$. In such a game the set of players is represented by the set of firms $N$ and every firm's strategy set is defined as

$$
Y_{i}=\left\{y_{i} \in R_{+}: y_{i} \leq \bar{y}_{i}\right\}
$$

where $\bar{y}_{i}$ is a capacity constraint. For every coalition of firms $S \subseteq N$, we can equivalently define the coalitional strategy set $Y_{S}=\prod_{S} Y_{i}$. We make the following standard assumptions:

A.1 The function $\pi_{i}(\cdot)$ and $C_{i}(\cdot)$ are twice continuously differentiable for every $i=1, \ldots, n$;

A.2 For every $i \in N$, the capacity constraint $\bar{y}_{i}<\infty$ determines the maximum production level;

A.3 For every $i \in N, p^{\prime \prime}(\cdot) y_{i}+p^{\prime}(\cdot)<0$ and $p^{\prime}(\cdot)-C_{i}^{\prime \prime}<0$.

Definition 1: A (Cournot) Nash equilibrium of $G$ is a strategy profile $y^{*}$ such that, for all $i \in N, y_{i}^{*} \in Y_{i}$ and, for all $y_{i} \in Y_{i}, \pi_{i}\left(y^{*}\right) \geq \pi_{i}\left(y_{i}, y_{-i}^{*}\right)$.

Proposition 1: There exists a unique (Nash) equilibrium of the game $G$.

Proof: By Assumptions A.1, A.2 and A.3 every player's pay-off functions is continuous in the strategy profile $y_{N}$ and strictly concave on $y_{i}$. Strategy sets are non-empty, compact and convex $\left(\left(y_{i} \leq \bar{y}_{i}<\infty\right)\right.$, so that existence of a Nash equilibrium follows. Uniqueness is proved as follows. By Assumption A.3, the function $\Phi\left(y_{i}, y\right) \equiv p^{\prime}(y) y_{i}+p(y)-C_{i}^{\prime}\left(y_{i}\right)$ is decreasing both in $y_{i}$ 
and in $y$. In fact, $\partial \Phi\left(y_{i}, y\right) / \partial y_{i}=p^{\prime}-C_{i}^{\prime \prime}<0$ and $\partial \Phi\left(y_{i}, y\right) / \partial y=p^{\prime \prime} y_{i}+p^{\prime}<0$. Suppose now that there exist two Nash Equilibria $\left(y_{1}^{1}, \ldots, y_{n}^{1}\right)$ and $\left(y_{1}^{2}, \ldots, y_{n}^{2}\right)$ of $G$. Equilibrium conditions require that, for each $i$

$$
\Phi\left(y_{i}^{1}, y^{1}\right)=0
$$

and

$$
\Phi\left(y_{i}^{2}, y^{2}\right)=0
$$

Thus, if $y_{i}^{1}>y_{i}^{2}$, then $y^{2}>y^{1}$. This in turns implies that $y_{j}^{1}>y_{j}^{2}$ for all $j$, contradicting the fact that $y^{2}>y^{1}$. Therefore, it must be that $y_{i}^{1}=y_{i}^{2}$ for all $i \in N$.

\section{Industry-wide Agreements}

In this section we concentrate on industry-wide collusive agreements-i.e. cartels that comprise all firms in the industry. A stable collusive agreements distributes to its members enough profits to discourage the formation of alternative agreements by subcoalitions of firms. The stability of an industrywide cartel can be formulated in terms of the existence of core imputations in an appropriately defined cooperative game in characteristic function.

\subsection{Cooperative Games and Coalitional Worths}

The purpose of a cooperative game is to describe the strategic possibilities of players and coalitions in a bargaining situation. Cooperative games abstract from the details of the strategic environment, and build directly on a specification of what each coalition would be able to achieve without the help of outside players (that, should negotiations fail). These coalitional worths act as outside options that players consider in the bargaining process.

Definition 2: A cooperative game with transferable utility (TU cooperative game) is a pair $(N, v)$, where $N=\{1,2, \ldots, i, \ldots, N\}$ is a finite set of players and $v: 2^{N} \rightarrow \mathcal{R}_{+}$is a mapping (characteristic function) assigning a value or worth to every non-empty feasible coalition $S \in 2^{N}$. $^{3}$

As we said, the worth $v(S)$ is the pay-off that coalition $S$ would expect to receive if its members were to jointly cease to cooperates with the remaining players in $N \backslash S$. An imputation for the game $(N, v)$ specifies the way in which the aggregate pay-off is distributed across players, and is a vector $\mathbf{z} \in \mathcal{R}_{+}^{n}$ such that $\sum_{i \in N} z_{i} \leq v(N)$ (feasibility) and $z_{i} \geq v(\{i\})$ (individual rationality) for all $i \in N$.

\footnotetext{
${ }^{3}$ Here we mainly deal with games with transferable utility. In games without transferable utility, the worth of a coalition associates with each coalition a players' utility frontier (a vector of utilities). 
The core of a cooperative game consists of all imputations which are robust to coalitional deviations, i.e. which distribute to each coalition $S$ at least its worth $v(S)$ in the game.

Definition 3: The core of a TU cooperative game $(N, v)$ is the set of all imputations $\mathbf{z} \in \mathcal{R}_{+}^{n}$ such that $\sum_{i \in S} z_{i} \geq v(S)$ for all $S \subseteq N$.

In this section we will review how the notion of core of a cooperative game has been used to investigate the stability of industry-wide agreements. The fact that, in the present Cournot game, only industry-wide agreements are candidate for core is straightforward: since the grand coalition $N$ generates more pay-off than any other partition of the set of players, $N$ would profitably object to any imputation proposed by such partition, and distribute the monopoly profit across firms in the appropriate way. In other words, the notion of core of a cooperative game is only apt to investigate under which conditions firms can collude by means of industry-wide agreements. Other notions of stability and game forms which admit the formation of smaller cartels are discussed in the next section.

When trying to apply the notion of core to our Cournot game, we note that the implicit strategic independence of firms' profits poses a problem in defining the worth $v(S)$ for a generic coalition $S$. In fact, the profit that $S$ can achieve by itself crucially depend on the way in which firms outside $S$ are organized. This suggests that deriving a function $v$ for the Cournot oligopoly game requires assumptions on the pattern of agreements that would emerge among firms in $M \backslash S$ (or, more precisely, are expected to emerge) should $S$ drop from the industry-wide agreement. In what follows we discuss the main approaches taken in the literature, and the implications of these approaches for the stability of an industry-wide cartel.

\section{$3.2 \alpha$ - and $\beta$-characteristic functions}

The concepts of $\alpha$ - and $\beta$-core, formally studied by Aumann (1967), are based on von Neumann and Morgenstern's (1944) early proposal of representing the worth of a coalition as pay-off it can guarantee its members in the underlying strategic form game. Accordingly, the characteristic function $v(S)$ for an oligopoly game is obtained by assuming that firms outside a deviating coalition $S$ act in order to minimize the profit of firms in $S$. The $\beta$-characteristic function assumes that members of $S$ choose their strategy after the other firms:

$$
v_{\beta}(S)=\min _{y_{N \backslash S}} \max _{y_{S}} \sum_{i \in S} \pi_{i}\left(y_{S}, y_{N \backslash S}\right)
$$

and represents what firms in $S$ cannot be prevented from getting. Alternatively, if members of $S$ move first, we have 


$$
v_{\alpha}(S)=\max _{y_{S}} \min _{y_{N} \backslash S} \sum_{i \in S} \pi_{i}\left(y_{S}, y_{N \backslash S}\right)
$$

denoted $\alpha$-characteristic function, which represents what firms in $S$ can guarantee themselves, when they expect a retaliatory behaviour from the complement coalition $N \backslash S{ }^{4}$

When the underlying strategic form game $G$ is zero-sum, (1) and (2) coincide. In the present oligopoly game they differ and $v_{\alpha}(S)<v_{\beta}(S)$ for all $S \subset N$.

Both the $\alpha$ - and the $\beta$-characteristic functions are based on expectations (by $S$ ) of irrational behaviour by the firms in $N \backslash S$. To be sure, the minimizing behaviour of outside firms is here not meant to represent the expectation of $S$ but rather as a mathematical way to determine the lower bound of $S$ 's aggregate pay-off). Still, this approach has important drawbacks, as the heavy retaliations that follow coalitional objections typically yield very large cores.

\subsection{Simultaneous Interaction among Coalitions: the $\gamma$ and $\delta$-characteristic Function}

Another way to define the characteristic function in games with externalities is to assume that in the event of a deviation from $N$, a coalition $S$ plays $\grave{a} l a$ Nash with the remaining firms. ${ }^{5}$ Here, different approaches assume different ways in which firms in $M S$ get organized before setting quantities. The $\gamma$-approach assumes that outside firms cease to collude altogether, and remain organized as singletons. Consequently, the strategy profile induced by the deviation of a coalition $S \subset N$ is the Cournot equilibrium among $S$ and each individual firms in $M S$. This is the set-up implicitly underlying papers like Salant et al. (1983) and Rajan (1989) to analyse the profitability of firms' collusion. Thus, the characteristic function $v_{\gamma}(S)$ can be defined for every $S \subseteq N$ as

$$
v_{\gamma}(S)=\sum_{i \in S} \pi_{i}\left(y_{S}^{*},\left\{y_{j}^{*}\right\}_{j \in N \backslash S}\right)
$$

where

$$
y_{S}^{*}=\underset{y_{S} \in Y_{S}}{\arg \max } \sum_{i \in S} \pi_{i}\left(y_{S},\left\{y_{j}^{*}\right\}_{j \in N \backslash S}\right)
$$

and $\forall j \in N \backslash S$,

\footnotetext{
${ }^{4}$ Note that firms outside $S$ are treated as one coalition, so the implicit assumption here is that firms in $M S$ stick together after $S$ departure from the grand coalition $N$.

${ }^{5}$ This way to define the worth of a coalition as a non-cooperative equilibrium pay-off of a game played between coalitions was first proposed by Ichiishi (1983). 


$$
y_{j}^{*}=\underset{y_{j} \in Y_{j}}{\arg \max } \pi_{j}\left(y_{S}^{*},\left\{y_{k}^{*}\right\}_{k \in(N \backslash S) \backslash\{j\}}, y_{j}\right)
$$

where $y^{*}=\left(y_{1}^{*}, \ldots, y_{n}^{*}\right)$ is characterized by the following $n$ first-order conditions (FOCs):

$$
\begin{aligned}
& p\left(y^{*}\right)+p^{\prime}\left(y^{*}\right) \sum_{i \in S} y_{i}=C_{i}^{\prime}\left(y_{i}^{*}\right) \quad \text { for all } i \in S \\
& p\left(y^{*}\right)+p^{\prime}\left(y^{*}\right) y_{j}^{*}\left(y_{S}^{*}\right)=C_{j}^{\prime}\left(y_{j}^{*}\right) \quad \text { for all } j \in N \backslash S
\end{aligned}
$$

An alternative approach assumes that firms react to the formation of coalition $S$ by forming the complementary coalition $N \backslash S$. This approach yields the following $\delta$-characteristic function:

$$
v_{\delta}(S)=\sum_{i \in S} \pi_{i}\left(y_{S}^{*}, y_{N \backslash S}^{*}\right)
$$

where

$$
\begin{aligned}
& y_{S}^{*}=\underset{y_{S} \in Y_{S}}{\arg \max } \sum_{i \in S} \pi_{i}\left(y_{S}, y_{N \backslash S}^{*}\right) \\
& y_{N \backslash S}^{*}=\arg \max _{y_{N \backslash S} \in Y_{N \backslash S}} \sum_{j \in N \backslash S} \pi_{j}\left(y_{S}^{*}, y_{N \backslash S}\right)
\end{aligned}
$$

In both cases, for (3) and (8) to be well defined, the Nash equilibrium of the strategic form game played among coalitions must be unique. This can be shown to hold under the same assumptions as in Proposition 1 above.

\subsection{Sequential Interactions among Coalitions: the $\lambda$-characteristic Function}

Both the $\gamma$ - and the $\delta$-characteristic functions are obtained under an implicit assumption on the dynamics of coalitional deviations. In particular, it is there assumed that the choice of a joint strategy by $S$ in the underlying oligopoly game is made after the deviation takes place and the new coalition structure (in which $S$ is embedded and with respect to which a Nash equilibrium is defined) has emerged. In other terms, it is implicitly assumed that in a first stage coalition $S$ forms and remaining firms react either splitting up as singletons or merging; in a second stage, optimal strategies are simultaneously chosen both by the deviating coalition of firms and by excluded firms.

A different dynamic could also be envisaged, in which the deviating coalition sets its quantity before the remaining firms react to the deviation, reintroducing the temporal structure typical of $\alpha$ - and $\beta$-assumptions. ${ }^{6}$ If,

${ }^{6}$ See Currarini and Marini $(2003,2004)$ for more details. 
for instance, excluded firms are assumed to slip up into singletons (as in the $\gamma$ approach), a deviating coalition $S$ would moves first anticipating the optimal reaction of the fringe firms $M \backslash S$, who simultaneously choose their best response as singletons. The strategy profile associated with the deviation of a coalition $S$ would be in this case the Stackelberg equilibrium of the game in which $S$ is the leader and players in $M \backslash S$ are, individually, the followers. We denote this strategy profile as a Stackelberg equilibrium with respect to $S$. Formally, this is the strategy profile $\tilde{y}(S)=\left(\tilde{y}_{S}, y_{j}\left(\tilde{y}_{S}\right)\right)$ such that

$$
\tilde{y}_{S}=\underset{\tilde{y} \in Y_{S}}{\arg \max } \sum_{i \in S} \pi_{i}\left(y_{S},\left\{y_{j}\left(y_{S}\right)\right\}_{j \in N \backslash S}\right)
$$

and, $\forall j \in M S$,

$$
y_{j}\left(y_{S}\right)=\underset{y_{j} \in Y_{j}}{\arg \max } \pi_{j}\left(y_{S},\left\{y_{k}\left(y_{S}\right)\right\}_{k \in(N \backslash S) \backslash\{j\}}, y_{j}\right)
$$

Conditions under which there exists a Stackelberg equilibrium with respect to $S$ are now established. For every coalition of firms $S \subset N$ and strategy profile $y_{S} \in Y_{S}$, let $G\left(M S, y_{S}\right)$ denote the restriction of the game $G$ to the set of firms $M \backslash S$, given the strategy profile $y_{S}$.

Proposition 2: For every coalition of firms $S \subset N$ there exists a Stackelberg equilibrium with respect to $S$.

Proof: By condition (10) and Proposition 1, the strategy profile $\left\{y_{j}\left(y_{S}\right)\right\}_{j \in M S}$ is the unique Nash equilibrium of $G\left(N \backslash S, y_{S}\right)$. By the closedness of the Nash equilibrium correspondence (see, for instance, Fudenberg and Tirole, 1991, p. 30), the members of $S$ maximize a continuous function over a compact set (Assumption A.2); thus, by Weierstrass theorem, a maximum exists.

Using (9) and (10) we can then define the joint pay-off (or worth) of every coalition of firms $v_{\lambda}(S)$ in the sequential case as uniquely defined by the following:

$$
v_{\lambda}(S)=\sum_{i \in S} \pi_{i}\left(\tilde{y}_{S},\left\{y_{j}\left(\tilde{y}_{S}\right)\right\}_{j \in N \backslash S}\right)
$$

where $\left(\tilde{y}_{S}, y_{j}\left(\tilde{y}_{S}\right)\right)$ is a Stackelberg equilibrium with respect to $S$ and the vector $\left(\tilde{y}_{1}, \ldots, \tilde{y}_{n}\right)$ is fully characterized by the following $n$-FOCs:

$$
\begin{aligned}
& p(\tilde{y})+p^{\prime}(\tilde{y})\left(1+(n-s) y_{j}\left(\tilde{y}_{S}\right)\right) \sum_{i \in S} \tilde{y}_{i}=C_{i}^{\prime}\left(\tilde{y}_{i}\right) \quad \text { for all } i \in S \\
& p(\tilde{y})+p^{\prime}(\tilde{y}) y_{j}\left(\tilde{y}_{S}\right)=C_{j}^{\prime}\left(y_{j}\left(\tilde{y}_{S}\right)\right) \quad \text { for all } j \in N \backslash S
\end{aligned}
$$

where $y_{j}\left(\sum_{i \in S} \tilde{y}_{i}\right)$ is the Nash equilibrium strategy of each player in the game $G\left(N \backslash S, \tilde{y}_{S}\right)$. Obviously, $v_{\lambda}(S) \geq v_{\lambda}(S)$. Similarly, the $\gamma$-assumption can 
be modified by assuming that a deviating coalition $S$ plays as follower against all remaining players in $M \backslash S$ acting as singleton leaders. Obviously, the same can be done under the $\delta$-assumption.

\subsection{Some Results in a Linear Cournot Oligopoly}

We first introduce a linear oligopoly, i.e. an oligopoly game such that $p(y)=$ $\max \{a-b y, 0\}$ and, for every firm $i \in N, C_{i}\left(y_{i}\right)=c y_{i}$. The constraints on the parameters are: $a>c \geq 0$ and $b>0$.

3.5.1 $\alpha$ - and $\beta$-core. Under $\alpha$ - and $\beta$-assumptions, if either an individual firm or a group of firms leave the grand coalition $N$, the remaining firms play a minimizing strategy such that, for every $S \subset N, v_{\alpha}(S)=v_{\beta}(S)=0$. In this case, the core simply coincides with the set of Pareto-efficient imputations (see, for example, Zhao, 1999). The predictive power of the $\alpha$ - and $\beta$-core is, therefore, minimal for the oligopoly game.

3.5.2 $\gamma$-core and $\delta$-core. According to the definition (3), under the $\gamma$-assumption the worth of a group of firms $S$ is given by

$$
v_{\gamma}(S)=\sum_{i \in S}\left[p\left(y_{S}^{*}, y_{-S}^{*}\right) y_{i}^{*}-C_{i}\left(y_{i}^{*}\right)\right]
$$

For the linear case introduced above, this equals to

$$
v_{\gamma}(S)=\max _{y_{S}} \pi_{S}\left(y_{S},(n-s) y_{j}\right)=(a-b y) y_{S}-c y_{S}
$$

where, using the firms' symmetry within each coalition, $y=s y_{i}+(n-s) y_{j}$. As a result, the FOC of every coalition $S$ is

$$
a-2 b y_{S}-b(n-s) y_{j}-c=0
$$

and its joint best reply function writes as

$$
y_{S}\left((n-s) y_{j}\right)=\frac{a-c-b(n-s) y_{j}}{2 b}
$$

Note that, by considering separately the FOC of every $i \in S$, we would obtain individual best reply functions:

$$
y_{i}\left((n-s) y_{j}\right)=\frac{a-c-b(n-s) y_{j}}{2 b s}
$$

and the analysis proceeds exactly as above summing up every $i$-firm's best reply. On the other hand, every firm $j \in M \backslash S$ playing as singleton maximizes

$$
\pi_{j}\left(y_{j},(n-s-1) \underset{k \in(N \backslash S) \backslash j}{y_{k}}, y_{S}\right)=\left(a-b y_{j}-b y_{S}-b(n-s-1) y_{k}\right) y_{j}-c y_{j}
$$


with FOCs

$$
a-2 b y_{j}-b(n-s-1) \underset{k \in(N \backslash S) \backslash j}{y_{k}}-b y_{s}-c=0
$$

Again, using firms' symmetry, every $j$ 's best reply can be written as

$$
y_{j}\left(y_{S}\right)=\frac{a-b y_{S}-c}{b(n-s+1)}
$$

Thus, by (15) and (16) we obtain

$$
y_{S}^{*}=\frac{a-c}{b(n-s+2)} \quad \text { and } \quad y_{j}^{*}=\frac{a-c}{b(n-s+2)}
$$

To obtain $v_{\gamma}(S)$, we first compute market price as

$$
p\left(y^{*}\right)=a-b y_{S}^{*}-b(n-s) y_{j}^{*}=\frac{a+(n-s+1) c}{(n-s+2)}
$$

and then

$$
v_{\gamma}(S)=\sum_{i \in S} \pi_{i}\left(y^{*}\right)=\pi_{S}=p\left(y^{*}\right) y_{S}^{*}-c y_{S}^{*}=\frac{(a-c)^{2}}{b(n-s+2)^{2}}
$$

Note that, for $s=n$,

$$
v_{\gamma}(N)=\frac{(a-c)^{2}}{4 b}
$$

Proposition 3: In the linear quantity oligopoly game, the $\gamma$-core is non-empty and strictly includes the equal split allocation.

Proof: We know from (18) and (19) that

$$
v_{\gamma}(N)=\frac{(a-c)^{2}}{4 b}
$$

and

$$
v_{\gamma}(S)=\frac{(a-c)^{2}}{b(n-s+2)^{2}}
$$

Without loss of generality we normalize $(a-c)^{2} / b=1$, so that the equal-split allocation gives to each firm in the industry-wide agreement $\{N\}$ a pay-off of $v_{\gamma}(N) /|N|=1 / 4 n$, where $n=|N|$. Consider now the equal-split allocation of any coalition of firms $S, v_{\gamma}(S) /|S|=1 / s(n-s+2)^{2}$, where $s=|S|$. For any 
distribution of the coalition worth $v_{\gamma}(S)$, at least one player in $S$ cannot get a pay-off higher than $1 / s(n-s+2)^{2}$. This implies that a coalition $S$ can improve upon the equal split allocation in $N$ if and only if

$$
\frac{1}{s(n-s+2)^{2}}>\frac{1}{4 n}
$$

Straightforward calculations show that the above inequality is satisfied respectively for

$$
\begin{aligned}
& s>n \\
& s<2+\frac{n-\sqrt{n^{2}+8 n}}{2}<1 \\
& s>2+\frac{n+\sqrt{n^{2}+8 n}}{2}>n
\end{aligned}
$$

and, hence, it is never satisfied for $1<s \leq n$. It follows that the equal-split allocation of the industry-wide merger $\{N\}$ belongs to the $\gamma$-core. To see that this allocation is strictly included in the $\gamma$-core, note that, since individual deviations assign to a player just $v_{\gamma}(\{i\})=1 /(n+1)^{2}<v_{\gamma}(N) / n=1 / 4 n$, different and unequal allocations also belong to the $\gamma$-core. In particular, any allocation giving to a player $i$ his worth $v_{\gamma}(\{i\})$ and $\left[v_{\gamma}(N)-v_{\gamma}(\{i\})\right] /(n-1)$ to any remaining player in $N$, cannot be objected.

The following result concerning the $\delta$-core can also be proved.

Proposition 4: In the linear quantity oligopoly, the $\delta$-core is empty.

Proof: Under the $\delta$-assumption, if a coalition of firms $S$ leaves the grand coalition, a simultaneous duopoly game is played between $S$ and remaining firms in $M \backslash S$ acting as a unique coalition. As a result, $v_{\delta}(S)=(1 / s)\left[(a-c)^{2} / 9 b\right]$ and the most profitable deviation is made by a single firm: $v(\{i\})=(a-c)^{2} / 9 b$, which is bigger than $v_{\delta}(N) / n=(a-c)^{2} / 4 n b$ for $n>2$. Therefore, the core is empty.

3.5.3 The Sequential Characteristic Function and the $\lambda$-core. According to (11), in the sequential case the worth of a coalition $S$ of firms can be defined as

$$
v_{\lambda}(S)=\sum_{i \in S}\left[p\left(\tilde{y}_{S},\left\{y_{j}\left(\tilde{y}_{S}\right)\right\}_{j \in N \backslash S}\right) \tilde{y}_{i}-C_{i}\left(\tilde{y}_{S}\right)\right]
$$

As before, the followers $j \in M S$ maximize their individual pay-offs $\pi_{j}$ for every given $y_{S}$ and their best replies are 


$$
y_{j}\left(y_{S}\right)=\frac{a-b y_{S}-c}{b(n-s+1)}
$$

The coalition $S$ acts as a leader and maximizes

$$
\sum_{i \in S} \pi_{i}\left(y_{i},(s-1) \underset{h \in S \backslash\{i\}}{y_{h}},(n-s) y_{j}\left(y_{S}\right)\right)
$$

which is equivalent to

$$
\pi_{S}\left((n-s) y_{j}\left(y_{S}\right)\right)=\left(a-b y_{S}-b(n-s) \frac{a-b y_{S}-c}{b(n-s+1)}\right) y_{S}-c y_{S}
$$

The FOC for the maximization problem of the coalition playing as a leader writes as

$$
a-2 b y_{S}-(n-s) \frac{\left(a-c-2 b y_{S}\right)}{(n-s+1)}-c=0
$$

from which

$$
\tilde{y}_{S}=\frac{a-c}{2 b} \quad \text { and } \quad y_{j}\left(\tilde{y}_{S}\right)=\frac{a-c}{2 b(n-s+1)}
$$

Therefore, in order to obtain $v_{\lambda}(S)$ we first compute the equilibrium price:

$$
p(\tilde{y})=a-b \tilde{y}_{S}-b(n-s) y_{j}\left(\tilde{y}_{S}\right)=\frac{a+2(n-s) c+c}{2(n-s+1)}
$$

and, hence,

$$
v_{\lambda}(S)=\pi_{S}\left(\tilde{y}_{S},(n-s) y_{j}\left(\tilde{y}_{S}\right)\right)=[p(\tilde{y})-c] \tilde{y}_{S}=\frac{(a-c)^{2}}{4 b(n-s+1)}
$$

Again, the worth of the grand coalition $(n=s)$ is obtained as

$$
v_{\lambda}(N)=\frac{(a-c)^{2}}{4 b}
$$

Proposition 5: In the linear quantity oligopoly, the equal-split efficient allocation is the unique element of the $\lambda$-core.

Proof: Again, without loss of generality, let $(a-c)^{2} / b=1$, so that the equalsplit allocation assigns to each firm in $N$ a pay-off of $v_{\lambda}(N) / n=1 / 4 n$ and $v_{\lambda}(S)$ $=1 / 4(n-s+1)$. We first show that the equal split allocation belongs to the core. Consider the value $v_{\lambda}(S) / s$ for any arbitrary coalition $S$. For every $S$ such that $s \leq n$ 


$$
\frac{v_{\lambda}(S)}{s}=\frac{1}{4 s(n-s+1)} \leq \frac{1}{4 n}=\frac{v_{\lambda}(N)}{n}
$$

In fact, the above inequality reduces to

$$
s(n-s+1) \geq n
$$

which is satisfied for $n \geq s$. Thus, if a coalition $S$ forms, at least one firm in $S$ will receive a pay-off not greater than $v_{\lambda}(S) / s$ and, therefore, less than or equal to $v_{\lambda}(N) / n$. This implies that the equal-split allocation is in the $\lambda$-core. To see that the equal-split is the unique allocation in the $\lambda$-core, note that (27) is satisfied with equality only for $s=n$ and $s=1$. This means that $v_{\lambda}(\{i\})=$ $v_{\lambda}(N) / n$ for all $i \in N$. Thus, consider an allocation $z^{\prime}$ different from the equal-split allocation. In $z^{\prime}$, some player $j$ will receive a pay-off $v_{j}<v_{\lambda}(N) / n$. Player $j$ can thus improve upon $z^{\prime}$ obtaining $v_{\lambda}(\{i\})=v_{\lambda}(N) / n$, which implies that $z^{\prime}$ is not in the $\lambda$-core.

The $\lambda$-core is non-empty and selects a unique symmetric allocation out of the $\gamma$-core, which instead includes a continuum of asymmetric allocations. The $\lambda$-core can be therefore viewed as a refinement of the $\gamma$-core, one that selects the 'most reasonable' optimal allocation (the equal-split) if applied to a symmetric quantity oligopoly setting.

\subsection{Oligopoly with Quadratic Costs}

We can now consider the case of firms with quadratic cost functions. We know from Rajan (1989) that, in this case, for $n=2, n=3$ and $n=4$ the $\gamma$-core is non-empty. We now show that this result does not extend to the $\lambda$-core. For simplicity, let $C_{i}\left(y_{i}\right)=y_{i}^{2} / 2$ and $p(y)=\max \{0,(a-y)\}$.

Proposition 6: In a linear demand and quadratic cost quantity oligopoly, the $\lambda$-core may be empty.

Proof: Straightforward calculations show that

$$
v_{\lambda}(N)=\frac{a^{2} n^{2}}{(1+2 n)^{2}}
$$

and

$$
v_{\lambda}(\{i\})=\frac{a^{2}\left(a^{2}+5 n-1\right)}{(n+1)(n+5)^{2}}
$$

It is easy to see that, for every $i \in N$ and $n \geq 2, v_{\lambda}(\{i\})=v_{\lambda}(N) / n$ and this proves that any firm can improve upon the equal-split allocation by deviating as singleton. This, in turn, implies that the $\lambda$-core is empty. 


\section{Stable Associations of Firms}

Even in contexts where the grand coalition maximizes the joint profit of players (as in the oligopoly game outlined in this survey), investigating the conditions under which smaller coalitions form and possibly coexist is of crucial importance. This both because of the widespread empirical evidence of fragmentation of cooperation, which is unlikely to merely reflect congestion or decreasing returns to size, and because it raises strategic considerations that are overviewed by the cooperative approach based on the core concept. In this section we first briefly review some of the games and equilibrium concepts used to study the emergence of multiple coalitions, and then we record the main results that these games and concepts imply for the oligopoly game.

4.0.1 Partition Function. We start by introducing the notion of partition function, a generalization of the characteristic function that suitable accommodates for the presence of strategic interaction in the game where players choose to cooperate (Thrall and Lucas, 1963). The partition function specifies the worth of each possible coalition as a function of the coalition structure (i.e. the partition of the players' set) in which it is embedded. Note that while the derivation of a characteristic function from a genuine strategic form game, discussed in the previous section, necessarily relied on assumptions on how outside players react to the formation of a coalition, the partition function simply specifies the pay-off of a coalition for every possible organisation of outside players. One can, of course, use the partition function as a primitive description of coalitional possibilities in the game, and obtain various characteristic functions under different assumptions about how players outside a forming coalition organize. This is the route we implicitly followed when defining the notions of $\gamma$ and $\delta$-characteristic functions. Here we will need to account for all possible partitions that result from players cooperative decisions, and the general tool of the partition function will serve this goal.

Definition 4: A partition function $w(S, P): 2^{N} \times \mathcal{P} \rightarrow \mathcal{R}_{+}$is a map assigning a worth to coalition $S$ embedded in partition $P \in \mathcal{P}$, for all $S_{k} \subseteq N$ and all $P=\left(S_{1}, S_{2}, \ldots, S_{m}\right)$ such that $S_{i} \cap S_{j}=\varnothing$ for every $i \neq j$ and $\cup_{k=1,2, \ldots, m} S_{k}=N$.

To derive a partition function from a strategic form game, one simply needs to associate with each possible partition a strategic profile for all players in the game. Since Ichiishi (1983), the modern theory of coalition formation adopts the view that players cooperate within coalitions and compete $a$ la Nash across coalitions. The partition function is therefore derived by associating to each coalition $S \in P$ the Nash equilibrium pay-off in the game where each coalition acts as a single aggregate player maximiz- 
ing its members' aggregate pay-off. In our oligopoly setting, this amounts to assuming that within each collusive cartel, firms maximize aggregate profit and compete à la Cournot with rival cartels.

4.0.2 Valuation. In modelling coalition formation as a non-cooperative game in which players choose partners with whom to cooperate, a full description of the individual pay-offs resulting from all possible coalition structure is needed. This can be done by specifying a fixed allocation rule distributing the worth of a coalition (as this is imputed by the partition function) to all its members. Such a fixed sharing rule gives rise to a per-member pay-off (valuation) mapping coalition structures into vectors of individual pay-offs.

Definition 5: A valuation is a vector of functions $v_{i}, i=1,2, \ldots, n$, assigning to each agent $i \in S \in P$ a real number, for all $S \subset N$ and $P \ni S$.

\subsection{Non-cooperative Games of Coalition Formation}

Most recent approaches have looked at the process of coalition formation as a strategy in a well defined game of coalition formation (see Bloch, 1997, 2003; Yi, 2003; Marini, 2009, for surveys). Within this new stream of literature, usually indicated as non-cooperative (or endogenous) coalition formation theory, the work by Hart and Kurz (1983) represents a seminal contribution. Other seminal contributions along these lines include Shenoy (1979), Bloch $(1995,1996)$, Ray and Vohra $(1997,1999)$ and Yi (1997). In all these works, cooperation is modelled as a two-stage process: at the first stage players form coalitions, while at the second stage coalitions interact in a well defined strategic setting. This process is formally described by a coalition formation game, in which a given rule of coalition formation maps players' announcements of coalitions into a well defined coalition structure, which in turns determines players' pay-offs according to a valuation. A basic difference among the various models lies on the timing assumed in the coalition formation game, which can be either simultaneous (e.g. Hart and Kurz, 1983; Ray and Vohra, 1997; Yi, 1997; Currarini and Marini, 2006) or sequential (Bloch, 1995; Ray and Vohra, 1999) as well as on the timing of the underlying strategic form game that, we will see, can be similarly modelled as simultaneous or sequential.

\subsubsection{Hart and Kurz's Games of Coalition Formation. Hart and Kurz} adopt as a valuation a general version of the Owen value for TU-games (Owen, 1977), i.e. a Shapley value with a priori coalition structures, that they call coalitional Shapley value, and that assigns to every coalition structure a pay-off vector $\varphi_{i}(P)$ in $\mathcal{R}^{N}$, such that (by an efficiency axiom) $\sum_{i \in N} \varphi_{i}(P)=v(N)$. Given this valuation, the game of coalition formation is modelled as a game in which each player $i \in N$ announces a coalition $S$ to 
which he would like to belong; for each profile $\sigma=\left(S_{1}, S_{2}, \ldots, S_{n}\right)$ of announcements, a partition $P(\sigma)$ of $N$ is induced. The rule $P(\sigma)$ is clearly a crucial issue for the prediction of which coalitions will emerge in equilibrium. Hart and Kurz's game $\Gamma$ predicts that a coalition forms if and only if all its members have declared it (hence the name of unanimity rule commonly used to describe the game). Formally:

$$
P(\sigma)=\left\{S_{i}(\sigma): i \in N\right\}
$$

where

$$
S_{i}(\sigma)= \begin{cases}S_{i} & \text { if } S_{i}=S_{j} \text { for all } j \in S_{i} \\ \{i\} & \text { otherwise }\end{cases}
$$

The alternative game $\Delta$ predicts instead that a coalition $T$ emerges if and only if all its members have declare the same coalition $S$ (which may, in general, differs from $T$ ). Formally:

$$
P(\sigma)=\left\{S \subset N: i, j \in S \text { if and only if } S_{i}=S_{j}\right\}
$$

Note that these two rules of coalition formation are 'exclusive' in the sense that every player in a coalition has announced the list of its members. Moreover, in the game $\Gamma$ this list has to be approved unanimously by all coalition members. In addition, it can be noticed that the two rules generate different partitions once a player decides to deviate from a coalition: in the $\Gamma$-game, remaining players split-up in singletons; in the $\Delta$-game, they stick together.

A stable coalition structure for the games $\Gamma$ and $\Delta$ is defined as a partition induced by an equilibrium strategy profile in the game. We first define the notion of strong Nash equilibrium, to be applied to the games $\Gamma$ and $\Delta$ as a coalitional refinement of the Nash equilibrium concept.

Definition 6: A strategy profile $\hat{x} \in X_{N}$ for a game in strategic form $G$ is a strong Nash equilibrium (SNE) if there exists no $S \subset N$ and $x_{S}^{\prime} \in X_{S}$ such that

$$
\begin{aligned}
& u_{i}\left(x_{S}^{\prime}, \hat{x}_{N \backslash S}\right) \geq u_{i}(\hat{x}) \quad \forall i \in S \\
& u_{h}\left(x_{S}^{\prime}, \hat{x}_{N \backslash S}\right)>u_{h}(\hat{x}) \quad \text { for some } h \in S
\end{aligned}
$$

Obviously, a SNE is both a Nash equilibrium and a Pareto-efficient strategy profile; in addition it satisfy the Nash stability requirement for every possible coalition. As a result, a SNE fails to exist in many economic problems and, in particular, whenever the Nash equilibria are not Pareto-efficient.

Definition 7: The partition $P$ is a Nash stable (strong Nash stable) coalition structure in the $\Gamma(\Delta)$ game of coalition formation if $P=P(\hat{\sigma})$ and $\hat{\sigma}$ is a Nash equilibrium (strong Nash equilibrium) of the game $\Gamma(\Delta)$. 
To apply the above games of coalition formation to the present oligopoly context, we need to first work out the valuations that result from market competition in any coalition structure.

Following our previous assumptions (see Section 1.2) we can derived the game $G(P(\sigma))$ from the strategic form oligopoly game $G$ by assuming that $Y_{S_{k}}=\prod_{i \in S_{k}} Y_{i}$ and $\pi_{S_{k}}=\sum_{i \in S_{k}} \pi_{i}$, for every coalition $S_{k} \in P$. We also assume the valuation $\pi_{i}=\pi_{S_{k}} /\left|S_{k}\right|$ assigning to each member the per capita pay-off of $S_{k}$. We can now compute the pay-off that a firm $i \in S_{k} \subset N$ obtains if all members of $S$ deviate from the strategy profile that induces the grand coalition by jointly declaring $S$. In this case, given the rules of the $\Gamma$-game, all remaining firms split up in singletons). We obtain

$$
\pi_{i}^{\gamma}\left(y^{*}\left(P\left(\sigma^{\prime}\right)\right)\right)=\frac{(a-c)^{2}}{s(n-s+2)^{2}}
$$

where $\sigma^{\prime}=\left(\{S\}_{i \in S},\{N\}_{j \in M S}\right)$.

Alternatively, the same coalitional deviation in the $\Delta$-game would result in the players outside $S$ forming the complementary coalition $M S$, and the per capita pay-off in $S$ is

$$
\pi_{i}^{\delta}\left(y^{*}\left(P\left(\sigma^{\prime}\right)\right)\right)=\frac{(a-c)^{2}}{9 s}
$$

We can now present the following proposition.

Proposition 7: In a linear quantity oligopoly, the industry-wide merger induced by the profile $\sigma=\left(\{N\}_{i \in N}\right)$ is a stable coalition structure of the $\Gamma$-game of coalition formation. It is not a stable coalition structure of the $\Delta$-game of coalition formation.

Proof: It can be easily verified that

$$
\pi_{i}^{\gamma}\left(y^{*}(P(\{N\}))\right)=\frac{(a-c)^{2}}{4 n} \geq \pi_{i}^{\gamma}\left(y^{*}(P(\{S\}))\right)=\frac{(a-c)^{2}}{s(n-s+2)^{2}}
$$

for every $s \leq n$ and, therefore, the $\gamma$-stability of the whole industry agreement (i.e. the strong Nash stability of announcement profile $\sigma=\left(\{N\}_{i \in N}\right)$ always holds for the linear quantity oligopoly. Moreover,

$$
\pi_{i}^{\gamma}\left(y^{*}(P(\{N\}))\right)=\frac{(a-c)^{2}}{4 n}<\pi_{i}^{\delta}\left(y^{*}(P(\{S\}))\right)=\frac{(a-c)^{2}}{9 s}
$$

for $s<\frac{4}{9} n$. Therefore, if the firms participate to a merger smaller than about 40 per cent of the market and competing with the coalition of remaining firms, they can obtain a higher profit than in the industry merger. Therefore $\{N\}$ is not stable under the $\Delta$-coalition formation game. 
In the $\Gamma$-game of coalition formation, smaller mergers can be sustained as Nash equilibria, as the next proposition illustrates.

Proposition 8: In linear quantity oligopoly, every coalition structure formed by one association of firms greater than 80 per cent of the whole market and competing with the fringe of remaining firms is a Nash stable coalition structure of the $\Gamma$-game when induced by the announcement profile $\sigma=\left(\{S\}_{i \in S},\{j\}_{j \in M S}\right)$.

Proof: Under the $\Gamma$-game of coalition formation if a firm deviates individually from the coalition structure $P=\left(\{S\},\{j\}_{j \in M S}\right)$, it will induce the coalition structure made of all singleton firms, i.e. $P^{\prime}=\left(\{i\}_{i \in N}\right)$. As a result,

$$
\pi_{i}^{\gamma}\left(y^{*}\left(\{S\},\{j\}_{j \in N \backslash S}\right)\right)=\frac{(a-c)^{2}}{s(n-s+2)^{2}} \geq \pi_{i}^{\gamma}\left(y^{*}\left(\{i\}_{i \in N}\right)\right)=\frac{(a-c)^{2}}{(n+1)^{2}}
$$

for $s \geq(2 n+3-\sqrt{4 n+5}) / 2 \simeq 0.8 n$ (as in Salant et al., 1983).

4.1.2 Sequential Games of Coalition Formation. Bloch $(1996,1997)$ introduces a sequential coalition-formation game with infinite horizon in which, as in the $\Gamma$-game of Hart and Kurz (1983), a coalition forms if and only if all its members have agreed to form exactly that coalition. The sequence of moves of the coalition formation game is organized as follows. At the beginning, the first player (according to a given ordering) makes a proposal for a coalition to form. Then, the player on his list with the smallest index accepts or rejects her proposal. If he accepts, it is the turn of the following player on the list to accept or reject. If all players on the list accept the first player's proposal, the coalition is formed and the remaining players continue the coalition formation game, starting with the player with the smallest index who thus makes a proposal to remaining players. If any of the players has rejected the first player's proposal, the player who first rejected the proposal starts proposing another coalition. Once a coalition forms, it cannot break apart or merge with another player or a coalition of players. Bloch (1996) shows that this game yields the same stationary subgame perfect equilibrium coalition structure as a much simpler 'size-announcement game', in which the first player announces the size of his coalition and the first $s_{1}$ players accept; then player $i_{s_{1}+1}$ proposes a size $s_{2}$ coalition and this is formed and so on, until the last player is reached. This equivalence is basically due to the $e x$ ante symmetry of players. It can also be shown that this size-announcement game possesses a generically unique subgame perfect equilibrium coalition structure.

For a linear Cournot oligopoly with more than two firms, Bloch's (1996) proves that his sequential game yields a generically unique subgame perfect equilibrium. This is expressed in the next proposition. 
Proposition 9: In a linear quantity oligopoly, the coalition structure $P=(\{S\}$, $\{j\}_{j \in M S}$ ), with $s=|S|$ equal to the first integer following $(2 n+3-\sqrt{4 n+5}) / 2$, is the unique subgame perfect equilibrium of the infinite-horizon sequential game of coalition formation.

The explanation is as follows. We know that when a merger of size $s$ is formed in a Cournot market, the equal-split pay-off of each firm $i \in S$ in the merger is $\pi_{i}\left(y^{*}\left(\{S\},\{j\}_{j \in M S}\right)\right)=(a-c)^{2} / s(n-s+2)^{2}$ which is greater than the usual Cournot profit $\pi_{i}\left(y^{*}\left(\{i\}_{i \in N}\right)\right)=(a-c)^{2} / s(n-s+1)^{2}$ only for $s>(2 n+3-\sqrt{4 n+5}) / 2$, which is the well-known 80 per cent market size found in Salant et al. (1983). When a merger of size $s$ is in place, each independent firm outside the merger earns a higher profit than every member of the merger, equal to $\pi_{j}\left(y^{*}\left(\{S\},\{j\}_{j \in M S}\right)\right)=(a-c)^{2} /(n-s+2)^{2}$. Therefore, in the sequential game of coalition formation, the first firms choose to remain independent and free-ride on the merger formed by subsequent firms. When the number of remaining firms is exactly equal to the Salant et al.'s (1983) minimal profitable merger size they will prefer to merge, as it is no longer profitable to remain independent.

4.1.3 Equilibrium Binding Agreement. Ray and Vohra (1997) propose a different stability concept. In this solution concept, players start from some coalition structures and are only allowed to break coalitions to smaller ones. The deviations can be unilateral or multilateral (i.e. several players can deviate together). The deviators take into account future deviations, both by members of their own coalitions and by members of other coalitions. Deviations to finer partitions must be credible, i.e. stable themselves, and therefore the nature of the definition is recursive. We can start with a partition $P$ and we can denote by $B(P)$ all coalition structures that are finer than $P$. A coalition $P^{\prime} \in B(P)$ can be induced from $P$ if $P^{\prime}$ is formed by breaking a coalition in $P$. A coalition $S$ is a perpetrator if it can induce $P^{\prime} \in B(P)$ from $P$. Obviously, $S$ is a subcoalition of a coalition in $P$. Denote the finest coalition structure, such that $|S|=1$ for all $S$, by $P_{0}$. There are no deviations allowed from $P_{0}$ and therefore $P_{0}$ is by definition stable. Recursively, suppose that for some $P$, all stable coalitions were defined for all $P^{\prime} \in B(P)$, i.e. for all coalition structures finer than $P$. Now, we can say that a strategy profile (say a quantity profile of our oligopoly game) associated to a coalition structure $y(P)$ is sequentially blocked by $y\left(P^{\prime}\right)$ for $P^{\prime} \in B(P)$ if (i) there exists a sequence $\left\{y\left(P_{1}\right), y\left(P_{2}\right), \ldots, y\left(P_{m}\right)\right\}$ with $y\left(P_{1}\right)=y(P)$ and $y\left(P^{\prime}\right)=y\left(P_{m}\right)$; (ii) for every $j=2, \ldots, m$, there is a deviator $S_{j}$ that induces $P_{j}$ from $P_{j-1}$; (iii) $y\left(P^{\prime}\right)$ is stable; (iv) $P_{j}$ is not stable for any $y\left(P_{j}\right)$ and $1<j<m$; (v) $\pi_{i}\left(y\left(P_{0}\right)\right)>$ $\pi_{i}\left(y\left(P_{j-1}\right)\right)$ for all $i \in S_{j}$ and $j=2, \ldots, m$.

Definition 8: $y(P)$ is an equilibrium binding agreement if there is no $y\left(P^{\prime}\right)$ for $P^{\prime} \in B(P)$ that sequentially blocks $y(P)$. 
Applying the equilibrium binding agreement to the linear oligopoly game, mix results are obtained.

Proposition 10: In a three-firm oligopoly beside $P_{0}=(\{1\},\{2\},\{3\})$, which is by definition stable, also the grand coalition strategy profile $y(P)$ with $P=(\{1,2,3\})$ is an equilibrium binding agreement. With $n$-firms there exists a cyclical pattern, in which the grand coalition may or not be stable. For $n=$ $3,4,5$ it is stable, but not for $n=6,7,8$. For $n=9$ is again stable and so on, with a somehow unpredictable pattern.

As explained by the authors, 'The grand coalition survives if there exist large zones of instability in intermediate coalition structures' (Ray and Vohra, 1997, p. 73).

\subsection{Endogenous Timing in Coalition Formation}

As noted by Huck et al. (2005b), one way to reconcile the theory of mergers in quantity oligopoly with some well-known empirical facts is to remove the assumption that merging firms set their quantities simultaneously with the other competitors. If firms affiliated to a merger can freely inform each others of their decisions whereas other firms do not possess the same information, mergers can act as Stackelberg leaders with respect to external firms. This would help the model to match a few empirically observed facts, e.g. the existence of advantageous horizontal mergers even with no convex costs (Office of Fair Trading, 1999), the welfare gains from mergers (see, for example, Federal Trade Commission, 1999) and the negative externalities for the external firms as result of a merger (Banerjee and Eckard, 1998).

Given the relevance of timing for mergers, in this section we model endogenous timing (see, for the case of two firms, Hamilton and Slutsky, 1990) within the framework of coalition formation. ${ }^{7}$ As in the extended game with observable delay by Hamilton and Slutsky (1990), we add to the oligopoly game a preplay stage $t_{0}$ in which every firm $i \in N$ makes an announcement $\sigma_{i}=(S, \tau) \in 2^{N} \times\left\{t_{1}, t_{2}\right\}$ that specifies both its preferred coalition and time of play. The announcements' profile $\sigma=\left(\sigma_{1}, \sigma_{2}, \ldots, \sigma_{n}\right)$ for the $n$ firms induces a partition endowed with a given timing of play (a timing coalition structure) $P^{\tau}=\left(S_{1}^{\tau}, S_{2}^{\tau}, \ldots, S_{k}^{\tau}, \ldots, S_{m}^{\tau}\right)$, using Hart and Kurz's (1983) $\Gamma$ or unanimity rule (see above). Formally:

$$
P^{\tau}(\sigma)=\left(S_{1}^{\tau}, S_{2}^{\tau}, \ldots, S_{k}^{\tau}, \ldots, S_{m}^{\tau}\right)
$$

such that

$\forall i \in N, i \ni S_{k}^{\tau}(\sigma)= \begin{cases}\left\{S_{k}^{\tau}\right\} & \text { if } \sigma_{i}=\sigma_{h}=\left(S_{k}^{\tau}, \tau\right) \quad \text { for all } i, h \in S_{k}^{\tau} \\ \{i\}^{\tau} & \text { otherwise }\end{cases}$

${ }^{7}$ For an application of this logic to the formation of R\&D cartels, see Marini et al. (2014).

C 2014 The University of Manchester and John Wiley \& Sons Ltd 
We will denote by $\mathcal{L}(\sigma)$ the set of all coalitions of firms that end up playing the basic game at stage one (leaders) according to the announcements' profile $\sigma$, and by $\mathcal{F}(\sigma)$ the set of all coalitions of firms that play the basic game at stage two (followers). As in Hamilton and Slutsky (1990), when either $\mathcal{L}(\sigma)=\{\varnothing\}$ (all firms announce $\tau=t_{2}$ ) or $\mathcal{F}(\sigma)=\{\varnothing\}$ (all firms announce $\tau=t_{1}$ ) the coalitions play simultaneously (at stage 1 or 2, respectively). As the following example show, the coalition formation rule described above unambiguously maps the set of players' announcements into the set of feasible timing coalition structures (CS) of the $n$ firms, that we denote by $\mathcal{P}^{\tau}(N)$.

Example 1: (Two-player case) $\forall i=1,2$, with $i \neq j$, each firm announcement set is given by

$$
\sum_{i}=\left[\left(\{i, j\}, t_{1}\right),\left(\{i, j\}, t_{2}\right),\left(\{i\}, t_{1}\right),\left(\{i\}, t_{2}\right)\right]
$$

The set of feasible timing coalition structures that can be induced by the 16 different announcement profiles $\sigma \in \Sigma_{1} \times \Sigma_{2}$, is

$$
\begin{aligned}
\mathcal{P}^{\tau}(N)=\left[\left(\{1,2\}^{t_{1}}\right),\left(\{1,2\}^{t_{2}}\right),\left(\{1\}^{t_{1}},\{2\}^{t_{1}}\right)\right. \\
\\
\left.\left(\{1\}^{t_{2}},\{2\}^{t_{2}}\right),\left(\{1\}^{t_{1}},\{2\}^{t_{2}}\right),\left(\{1\}^{t_{2}},\{2\}^{t_{1}}\right)\right]
\end{aligned}
$$

Note that, in general, the cardinality of $\mathcal{P}^{\tau}(N)$ can be determined by the formula

$$
\left|\mathcal{P}^{\tau}(N)\right|=\sum_{k=2}^{n-1} B(n, k) \cdot 2^{k}+B(n, 1) \cdot 2^{n}+B(n, n) \cdot 2
$$

where $B(n, k)$ is the corresponding Bell number (or Stirling number of second type), i.e. the number of ways a set of cardinality $n$ can be partitioned into exactly $k$ non-empty subsets (coalitions) $S \subset N .{ }^{8}$

A concept of stable timing coalition structure can thus be defined as a feasible $P^{\tau}(\sigma)$ induced by a strong Nash equilibrium $\hat{\sigma}$ of the coalition timing game

$$
C=\left(N,\left\{\Sigma_{i}, \pi_{i}\left(y\left(P^{\tau}(\sigma)\right)\right\}_{i \in N}\right)\right.
$$

What is basically required for stability is that no coalition of firms can improve upon this profile of announcement, thus inducing a different timingcoalition structure.

For a symmetric oligopoly with no discount it can be shown that:

${ }^{8}$ The set $\mathcal{P}^{\tau}$ becomes very large when the number of players increase. To give an example, for $N=\{1,2,3,4,5\},|\mathcal{P}(N)|=\sum_{k=2}^{n-1} B(5, k) \cdot 2^{k}+B(5,4) \cdot 2^{5}+B(5,5) \cdot 2=15 \cdot 2^{2}+25 \cdot 2^{3}+$ $10 \cdot 2^{4}+1 \cdot 2^{5}+1 \cdot 2=454$. 
(1) The announcement profile that induces the grand coalition of firms playing cooperatively at period two is a strong Nash equilibrium when firm actions are strategic complements (in the sense of Bulow et al., 1985);

(2) The announcement profile that induces the grand coalition of firms playing cooperatively at period one is a strong Nash equilibrium when firm actions are strategic substitutes.

The intuition behind these results is as follows. All firms playing simultaneously and cooperatively at stage two $\left(\{N\}^{t_{2}}\right)$ is stable if every individual firm acting as follower at stage $t_{2}$ is better off than any firm in any coalition acting as leader at stage $t_{1}$. If this is the case a deviating coalition $S \subset N$ from the grand coalition $\{N\}^{t_{2}}$ announcing either $\sigma_{S}^{\prime}=\left(\{S\}, t_{2}\right)$ or $\sigma_{S}^{\prime \prime}=\left(\{S\}, t_{1}\right)$ would induce either the simultaneous partition

$$
P^{\tau}\left(\sigma_{S}^{\prime}\right)=\left(\{S\}^{t_{2}},\{j\}_{j \in N \backslash S}^{t_{2}}\right)
$$

or the sequential partition

$$
P^{\tau}\left(\sigma_{S}^{\prime \prime}\right)=\left(\{S\}^{t_{1}},\{j\}_{j \in N \backslash S}^{t_{2}}\right)
$$

where in both cases all firms in $M S$ play as singletons. Note also that if $S$ cannot improve upon $\{N\}^{t_{2}}$ as leader in partition (32) it would not improve a fortiori by playing simultaneously in partition (31). Therefore, it is enough to show that in partition (32) all firms in $S$ (regardless its size) do not improve upon $\{N\}^{t_{2}}$. When firm actions in the market are strategic complements, it can be proved that the pay-off of a symmetric firm acting as singleton follower against the coalition $S$ playing as leader is always higher than the pay-off of every firm in $S .{ }^{9}$ Hence, given the efficiency of the grand coalition, it would be impossible for a coalition $S$ to improve by deviating as leader. Similarly, it can be shown that when firm actions are strategic substitutes a coalition $S \subset N$ made of followers is beaten by individual firms investing as leaders, and therefore the partition $\{N\}^{t_{1}}$-made by the grand coalition of firms investing at time $t_{1}$-is strong Nash stable.

4.2.1 Linear Quantity Oligopoly. In the case of linear quantity oligopoly, normalizing $(a-c)^{2} / b=1$, we can compute the profit of every firm in a generic coalition structure $P^{\tau}(\sigma)$ in which all associations of firms play simultaneously

$$
\pi_{i}\left(y^{*}\left(\left\{S_{k}\right\}_{k=1,2, \ldots, m}^{\tau}\right)\right)=\frac{1}{s_{k}\left(\left|P^{\tau}(\sigma)\right|+1\right)^{2}}
$$

where $\left|P^{\tau}(\sigma)\right|$ indicates the number of coalitions in coalition structure $P^{\tau}$, or as Stackelberg leaders $(L)$ and followers $(F)$ in a coalition structure with sequential timing:

${ }^{9}$ For a formal proof of this statement see Currarini and Marini (2003, 2004).

(C) 2014 The University of Manchester and John Wiley \& Sons Ltd 


$$
\begin{aligned}
& \pi_{i}^{\mathrm{L}}(\tilde{y}(\mathcal{L}(\sigma), \mathcal{F}(\sigma)))=\frac{1}{s_{k}^{\mathrm{L}}(|\mathcal{L}(\sigma)|+1)^{2}(|\mathcal{F}(\sigma)|+1)} \\
& \pi_{i}^{\mathrm{F}}(\tilde{y}(\mathcal{L}(\sigma), \mathcal{F}(\sigma)))=\frac{1}{s_{k}^{\mathrm{F}}(|\mathcal{L}(\sigma)|+1)^{2}(|\mathcal{F}(\sigma)|+1)^{2}}
\end{aligned}
$$

where $|\mathcal{L}(\sigma)|$ and $|\mathcal{F}(\sigma)|$ represent the number of coalitions playing as leaders and followers, respectively. The introduction of the endogenous timing shows that no intermediate merger structures of firms can be stable if they occur at time two. In this case a firm could, in fact, deviate as leader (announcing $\left.\sigma_{i}=\{i\}^{t_{1}}\right)$ and induce a coalition structure in which it plays as leader and all remaining firms (organized in various groups) play as follower. It can be proved that this new situation is at least as profitable for the leader as the equal-split monopoly profit and, therefore, dominates the pay-off obtained in any simultaneous (intermediate) coalition structure. The following proposition illustrates this point in detail. It also shows, from a different perspective, that the well-know Salant et al.'s (1983) minimum size condition must hold for a simultaneous merger to be stable at time $t_{1}$.

Proposition 11: In a linear quantity oligopoly the only Nash stable coalition structure at time $t_{2}$ is the grand coalition of firms. A coalition structures at time $t_{1}$ of the form $P^{t_{1}}=\left(\{S\}^{t_{1}},\{j\}_{j \in N \backslash S}^{t_{1}}\right)$ is Nash stable if and only if $s \geq 0.8 n$.

Proof: The first statement simply follows from the fact that any intermediate partition $P^{t_{2}}=\left(S_{1}^{t_{2}}, S_{2}^{t_{2}}, \ldots, S_{m}^{t_{2}}\right)$ can be profitably objected by one firm announcing its intention to play as leader at time $t_{1}$, i.e. declaring $\sigma_{i}=\{i\}^{t_{1}}$. In this case the other firms in merger $S_{k}^{t_{2}} \ni i$ would compete as individual followers at time $t_{2}$ whereas the remaining coalitions would play as followers. Expression (34) shows that the worst pay-off for a firm $i$ deviating as leader occurs when all remaining (follower) firms play as singletons. Thus, if we compare the pay-off obtained by an individual firm deviating as leader (when outside firms play as individual followers) to the per capita pay-off obtainable at the simultaneous coalition structure played at time $t_{2}$, we get

$$
\pi_{i}^{\mathrm{L}}\left(\tilde{y}\left(\{i\}^{t_{1}},\{j\}_{N \backslash\{i\}}^{t_{2}}\right)\right)=\frac{1}{4 n} \geq \pi_{i}\left(y^{*}\left(\left\{S_{k}\right\}_{k=1, \ldots, m}^{t_{2}}\right)\right)=\frac{1}{s_{k}\left(\left|P^{t_{2}}(\sigma)\right|+2\right)^{2}}
$$

which holds for $s_{k} \leq n$ and for any possible partition $P^{t_{2}}(\sigma)$. The expression above proves that in any intermediate coalition structure occurring at time $t_{2}$ a firm receives less than one individual leader regardless of the way followers organize in alliances. Only the grand coalition of firms playing at time $t_{2}$, i.e. $P^{t_{2}}=\{N\}^{t_{2}}$, cannot be profitably objected by an individual leader, since in this case the equal split monopoly pay-off and the leader's pay-off coincide. As a result, the grand coalition is the unique Nash stable coalition structure at time 
$t_{2}$. The second statement trivially follows from the fact that since a firm deviating from $P^{t_{1}}=\left(\{S\}^{t_{1}},\{j\}_{j \in N \backslash S}^{t_{1}}\right)$ ends up either playing as follower or, at best, simultaneously in a $n$-firm oligopoly, it follows that any individual deviation from a merger of size $s \geq 0.8 n$ can never be profitable.

Comparing our model to some of the existing literature on sequential mergers, we can observe that the case analysed by Huck et al. (2001) corresponds to the case of $m$ individual leaders playing against $(n-m)$ individual followers. In this specific case, if a leader and a follower merge and the two firms become one leader, their overall profit will increase. Using (34) and (35),

$$
\begin{aligned}
& \pi_{\{i, j\}}^{\mathrm{L}}(\tilde{y}(m, n-m-1))-\left[\pi_{i}^{\mathrm{L}}(\tilde{y}(m, n-m))+\pi_{i}^{\mathrm{F}}(\tilde{y}(m, n-m))\right] \\
& \quad=\frac{1}{(m+1)^{2}(n-m)}-\frac{1}{(m+1)^{2}(n-m+1)}-\frac{1}{(m+1)^{2}(n-m+1)^{2}} \\
& \quad=\frac{1}{(m+1)^{2}(n-m)(n-m+1)^{2}}>0
\end{aligned}
$$

A first observation is that, although it is efficient to aggregate one leader and one follower into one leading merger, their individual incentives may differ under the equal split allocation. In particular, simple calculations show that for a leader is never individually profitable to merge with a follower, in case they expect to share equally the future profits, even if the merger reduces the number of followers in the market. Moreover, our generalization based on (33)-(35) adds new elements to the analysis. A follower playing as singleton against a merger of leaders has an incentive to join the merger only if its size $s_{k}^{\mathrm{L}}$ is approximately smaller than one-half of the market. Only under this size the followers prefer to enter the merger rather than to play as singleton and free-ride on the merger. In fact,

$$
\pi_{j}^{\mathrm{F}}\left(\{S\}^{t_{1}},\{j\}_{j \in N \backslash S}^{t_{2}}\right)=\frac{1}{4\left(n-s^{L}+1\right)^{2}}<\pi_{i \in S}^{\mathrm{L}}\left(\{S\}^{t_{1}},\{j\}_{j \in N \backslash S}^{t_{2}}\right)=\frac{1}{s^{\mathrm{L}} 4\left(n-s^{\mathrm{L}}+1\right)}
$$

which is solved for $s^{\mathrm{L}}<(n+1) / 2$. Here, contrarily to Salant et al.'s (1983) the merger acting as leader has to be sufficiently small to become profitable to the followers.

\section{EXTENSIONS}

\subsection{Heterogenous Firms}

In order to preserve the tractability of the models, most of the wide literature on collusive agreements under oligopoly commonly assumes ex ante symmetry of firms in terms of both costs and demand. The main reason is that the ex post symmetry (i.e. after the merger) of firms' pay-offs is no longer guaranteed when coalitions of firms of different size compete in the market. If 
the analysis introduces additional sources of firms' asymmetry, it becomes extremely hard to obtain tractable results. This explains why the number of papers that have studied the formation of alliances between heterogeneous firms has been, so far, limited. For simplicity, we can organize the papers dealing with coalitional agreements among heterogeneous firms in three main groups: (i) works looking at the stability of mergers of heterogenous firms in simultaneous-move oligopolies (e.g. Ebina and Shimizu, 2009; Watanabe and Matsubayashi, 2013; Zhao, 2013); (ii) works looking at the stability of mergers of heterogeneous firms in sequential oligopolies (e.g. Escrihuela-Villar and Faulí-Oller, 2008; Driessen et al., 2011); (iii) works looking at the formation of cost-reducing alliances by heterogeneous firms in simultaneous-move oligopolies (Belleflamme, 2000).

(i) In a recent paper Zhao (2013) examines the stability of the grand coalition of firms as well of other coalition structures under the $\alpha-\gamma-\gamma$ and $\delta$-assumptions in a linear Cournot oligopoly with three firms having different marginal costs. The author assumes that, in an alliance, firms can produce at the lowest marginal cost (hypothesis known as transferrable technology). Zhao's (2013) main result is that whereas the $\alpha$-core is non-empty for all possible firms' cost-differentials, the $\delta$-core is non-empty only if either the two inefficient firms are sufficiently small compared with the efficient one or their cost-differentials are sufficiently high. It is also shown that when the cost reduction from the merger are large enough, the grand coalition of firms is socially efficient.

A number of papers have recently focused on the profitability and stability of mergers in quantity oligopoly games with asymmetrically differentiated goods. In a four-firm model, Ebina and Shimizu (2009) show that, when only mergers between two firms are allowed, the incentive to merge is stronger for firms producing the less differentiated goods. Moreover, if one group of firms merge, the incentive to merge faced by remaining firms increases. In a differentiated quantity oligopoly with three (or four firms), Watanabe and Matsubayashi (2013) show that for any degree of product differentiation the industry-wide merger is always stable under the $\gamma$-assumption. Under the $\delta$-assumption, the grand coalition may become stable only in presence of high product differentiation. This is because, if products are highly differentiated and a firm deviates from the grand coalition by expanding its output, the remaining firms (in the complementary coalition) do not reduce much their own outputs in response, and this makes the deviation unprofitable. Using a linear quantity oligopoly with symmetrically differentiated goods, Lekeas (2013) introduces a concept of core in which a deviating coalition expects the formation of at least a given number of coalitions (or more) among the remaining firms. The worth of a coalition is thus defined as the minimum worth that a coalition can obtain over all possible partitions of the remaining firms. It is proved that when goods are complements, the grand coalition is always stable (and the core non-empty) irrespective of the beliefs of the agents of any 
deviating coalition $S$. If goods are substitutes, the core is non-empty provided that a deviating coalition believes its opponents will form a sufficient number of coalitions. Since it was already proved (e.g. Currarini and Marini, 2003) that in all games in which players actions are strategic complements $\lambda$ - and $\gamma$-core are non-empty (see also Lardon, 2012) it does not come as a surprise that in a Cournot oligopoly game in which goods are complements (and actions strategic complements) the core is non-empty if remaining firms form a sufficient number of coalitions in response to a deviation.

(ii) In the Industrial Organization literature some papers have studied the propensity of firms to merge in a linear Stackelberg quantity setting. In a symmetric generalized Stackelberg oligopoly model, Daughety (1990) shows that a merger made by two followers and forming only one firm acting as leader can be profitable and welfare-enhancing. In the same setting Huck et al. (2001) shows that a merger between a leader and a follower is always profitable. Escrihuela-Villar and Faulí-Oller (2008) have extended the analysis to the case in which the firms acting as leaders are more efficient than the firms acting as followers. They then prove that the efficient leaders rarely have an incentive to merge. Mergers are shown to be profitable only in two cases: when a leader incorporates a follower; when two or more followers merge, provided that their marginal costs are big enough. This occurs because in this case all leaders reduce their equilibrium outputs and increase the market profitability as a result.

Driessen et al. (2011) study the non-emptiness of $\gamma$-core in a Stackelberg quantity oligopoly TU-game (i.e. the $\lambda$-core) with firms having different marginal costs. This paper provides necessary and sufficient condition under which the $\lambda$-core is non-empty and also shows that this condition is satisfied if and only if firms' marginal costs are not too heterogeneous. Thus, whereas demand heterogeneity works in favour of the stability of the grand coalition (see point (ii) above), cost heterogeneity works against.

(iii) Adopting Bloch's (1995) model of cost-reducing alliances in a Cournot oligopoly, Belleflamme (2000) explores the consequences of heterogeneous firms in a simultaneous open membership game of coalition formation. It is well known (e.g. Bloch, 1997; Yi, 1997) that, with symmetric firms, the only Nash equilibrium of the open membership game of coalition formation implies the formation of the grand coalition. This is because the benefits of cooperation increases linearly with the size of the coalition and, therefore, in an open membership game there is no reason to remain out of the industry-wide association of firms. Belleflamme (2000) shows that this result extends to the case with asymmetric associations but not to the case with symmetric associations and asymmetric firms. In particular, when firms obtain different benefits in joining an association, several associations might form or a pure strategy Nash equilibrium coalition structure might even fail to exists. When both associations and firms are allowed to be asymmetric, the author shows that, if at most two associations can form, there exists a coalition proof Nash equi- 
librium in which these two coalitions are formed and all members of the associations have a higher taste for the association than all non-members do.

\subsection{Information Sharing Agreements}

In this final section we wish to discuss the issue of private information in the context of oligopoly games, mergers and alliances. A recent contribution by Amir et al. (2009) has studied the effect of private information held by merging firms about the post-merger unit production cost, i.e. about efficiency gains from merging. The main point of the paper is to show that when efficiency gains are believed to exist with sufficiently high likelihood, then mergers become profitable even if such efficiency gains fail to materialize. The key ingredient here is the increased market power of the merger due to its private information about post-merger costs, and the consequent inability of fringe firms to fine-tune their market behaviour to the merger's true cost conditions.

A large theoretical body of work has investigated another aspect on which private information plays a role in oligopolies. This literature builds on the consideration that when oligopolistic firms have private information about either market demand or technological conditions, communication and cooperation can be beneficial even in the absence of collusion in pricing strategies. Firms may in fact face incentives to share their own private information prior to non-collusive market competition, either to all or to a subset of competitors. Understanding such incentives has strong policy relevance, as it can guide regulative intervention by suggesting whether evidence of information sharing should or should not be interpreted as evidence of market collusion (see Kuhn and Vives's (1995) report on the EU industry). For this reason this problem has received vast attention in the theoretical Industrial Organization literature, where game theoretic models of incomplete information have been employed to disentangle the forces that finally result in the incentives to disclose or share one's private information. Most papers have dealt with situations where information is shared prior to the realization of uncertainty (the ex-ante case), so that the decision of disclosing does not signal anything on one's own private information. There have been a few attempts to deal with the interim case, that we do not cover in this survey.

The technology of information sharing has been modelled in essentially two ways. In the strategic model, each firm decides whether to disclose its own information to other firms, and receives the information of all other disclosing firms irrespective of its own disclosure decision. This model is well described as a game in which firms unilaterally set their disclosure strategy, and expected pay-offs depend on the disclosure strategy of all firms in the market. In the contractual model, firms share information with competitors on a quid pro quo basis: by refusing to disclose one's own information firms 
also loose the information of other disclosing firms. In this model information is a 'club good' from which non-disclosing firms are excluded. In this sense, the contractual model leads itself to an analysis based on games of coalition formation, where firms can form information sharing coalitions and exclude other firms from their private information. Within this second approach, however, the literature has mostly looked at the bare comparison between the universal sharing of information (industry wide agreement) and the complete absence of sharing, interpreting the difference in expected pay-offs as the incentives to form a trade association for the industry. A few exceptions that we will discuss below have looked at the incentives to form smaller sharing coalitions.

A simple and basic model is sketched as follows. There are $n$ oligopolists producing with no cost, and a linear demand:

$$
p_{i}=(A+\tau)-y_{i}-\gamma \sum_{j \neq i} y_{j}
$$

where $A$ is a constant $\tau$ is a random variable distributed normally with zero mean and variance $t$. The parameter $\gamma$ measures the effect on the price faced by firm $i$ of the aggregate quantity produced by the other firms (an index of firms' products' differentiation $\gamma=1$ and $\gamma=0$ correspond to the polar cases of perfect substitutes and of perfectly differentiated goods, respectively).

Private information is modelled as follows. Each firm $i$ receives a private noisy signal $s_{i}$ about the state of the world $\tau$, with $y_{i}=\tau+\eta_{i}$, where the noise $\eta_{i}$ is normally distributed with zero mean, variance $u$ and covariance $u_{n} \geq 0$. In the strategic model, each firm decides whether to (or to what extent) disclose its private signal, and each firm observes its own signal and the signal disclosed by other firms, independently of its disclosure strategy. In the contractual model, an industry-wide agreement is the scenario where all firms share their private signal with all other firms, so that each firm takes its market decision observing all $n$ signals about the demand intercept. In the complete absence of information sharing, each firm $i$ takes its market decision observing only its private signal $s_{i}$. In both models, market competition (modelled as a second stage of a two-stage game) results in the Bayesian Nash equilibrium in which firms information depends on disclosure strategies in the first stage. It can be shown that a firm's equilibrium profit in the Cournot game is an affine function of the variance of its own equilibrium quantity.

One first key insight from the pioneering works of Novshek and Sonnenschein (1982), Clarke (1983), Vives (1985), Li (1985) and Gal-or (1985) is that firms competing on quantity face no incentive to share their private information on a common demand intercept demand, unless they produce highly differentiated products. ${ }^{10}$ In particular, when products are homoge-

\footnotetext{
${ }^{10}$ Raith (1996) provides a detailed analysis of the role of both the type (common versus private) and the precision of private information in determining incentives. 
neous $(\gamma=1)$ it is dominant not to disclose information in the strategic model, and it is not profitable to share information in an industry-wide association in the contractual model. The forces behind this result can be understood as follows. The exchange of private information on demand conditions has two main effects on equilibrium play. On one hand, firms receiving additional information refine their expectation about the state of the world; this effect is always beneficial in terms of expected profit. On the other hand, information sharing increases the correlation of strategies in equilibrium; this second effect is detrimental to profits when strategies are substitutes, and beneficial when strategies are complements. In the strategic model, Cournot oligopolists find it dominant to conceal their own private signal, since this avoids the second negative effect (due to strategic substitutability), without losing the first positive one. In the contractual model, concealing one's own information comes at the cost of loosing other firms' disclosed information, and incentives to share finally depend on the magnitude of the two effects above. In particular, the negative effect of increasing the correlation of strategies by disclosing becomes less and less important as products' differentiation increases and, as a consequence, as strategic substitution in the game is weakened. Similar considerations lead to the conclusion that Bertrand oligopolists (playing a game with strategic complements) always find it dominant to disclose their own information.

The conclusion that (at least under mild product differentiation) Cournot oligopolists find it optimal not to form an industry-wide agreement does not exhaust the analysis of cooperative information sharing in the contractual model. Indeed, even if industry-wide agreements are not profitable, smaller scale agreements, where members' information has the feature of a club good, may still be profitable. The issue of smaller scale agreements has been first raised by Malueg and Tsutsui (1996), where it is shown that not only industry-wide agreements can be profitable and immune to individual defections when products are strongly differentiated, but also that a coalitional agreement by a subset of firms can be stable to defections (more precisely, can be a coalition-proof Nash equilibrium). Their result is obtained in the framework of a three-firm model, and fails to predict information sharing of any kind when products are strongly homogeneous. In a recent contribution to this literature, Currarini and Feri (2013) have shown that the formation of smaller coalitions of firms can be profitable even in a linear Cournot model with perfectly homogeneous products. Their main result rests on the role of the conditional correlation of private signals on firms' incentives to share information in small coalitions. In terms of the above sketched model, they consider the case in which $u_{n}>0$. They show that the complete absence of information sharing is not a stable scenario when the formation of small coalitions is allowed, and some extent of information sharing is therefore a property of all equilibria. The basic intuition behind this result goes as follows. When firms' private information is (conditionally) correlated, 
the exchange of information within a small coalition of firms has the effect of refining these firms' expectation about all outside firms' signals (and behaviour). This refinement results from the assumed conditional correlation of signals, and comes at 'no cost', since it does not require any revelation of the sharing firms' information to the outside competitors. The magnitude of the resulting increase in expected profits is larger the larger the number of firms outside the sharing coalition. Hence the result: if signal are conditionally correlated and the number of firms is large enough, then there exists a subcoalition of firms for which information sharing is profitable.

\section{Concluding Remarks}

In this paper we have reviewed various approaches taken to investigate the emergence of firms' associations and market collusion in oligopoly. The particular focus of this survey was on the role of coalitions of firms both in the formation and in the dissolution of an agreement. We have identified two types of models. Those that study under which conditions an industry-wide agreement can emerge and be sustained, leading to a factual monopoly, and those that study conditions under which firms organize in smaller and possibly multiple coalitions, giving rise to a concentrated oligopoly structure. We have seen how the stability of an industry-wide agreements crucially depends on the conjectures that smaller coalitions make on the behaviour of outside players. In the linear Cournot model, pessimistic conjectures such as the $\alpha$ and $\beta$ or even the $\gamma$ generate stable industry-wide agreements, even when firms that defect from a cartel can exploit a first mover advantage, in which case stability requires an equal sharing of profits within the cartel. More optimistic conjectures such as the $\delta$ imply that collusion cannot be sustained in one-shot market interaction. Models that study the emergence of smaller and multiple coalitions of firms adopt stability notions that are either based on individual revisions by single firms (such as those based on external and internal stability) or that model coalition formation as a full-fledged game of announcements. We have seen that the well-known conjecture that only cartels covering for a large enough share of the market are stable is confirmed in most approaches, with the exception of models where timing is a crucial issue for how coalitions revise their strategies. In particular, when revisions can also affect the timing of play in a Cournot game, stable cartels need to include the whole industry, and imply that collusion is not delayed. A partial counterpart is obtained in Bertand competition, where strategies are complements and successful collusion requires a delay between the announcement and the implementation of strategies.

Future research on these issues seem to be directed towards a better mix of theoretical modelling and empirical evidence, naturally leading towards models that encompass crucial aspects of real markets such as firms' heterogeneity, uncertainty and private information. While heterogeneity is certainly 
a difficult aspect to incorporate in theoretical models, one possibly fruitful direction would be to work with statistical models, where equilibrium is derived as a function of firms' distribution, very much along similar lines as followed in the study of behaviour on networks. Interesting questions concerning the role of heterogeneity could be addressed in terms of first and second-order shifts in the distribution of firms' characteristics, possibly with results that would crucially depend on the strategic nature of firms' interaction (complements versus substitutes). The study of complex market structures with possibly intransitive relations (e.g. networks) would also add some understanding in contexts where firms' collaboration need not be limited on a single issue, and firms may collude with different partners in different markets. We leave these and other issues for our current and future research.

\section{REFERENCES}

Amir, R., Diamantoudi, E. and Xue, L. (2009). 'Merger Performance under Uncertain Efficiency Gains', International Journal of Industrial Organization, Vol. 27, pp. 264-273.

Aumann, R. (1967). 'A Survey of Games without Side Payments', in M. Shubik (ed.), Essays in Mathematical Economics, Princeton, Princeton University Press, pp. 3-27.

Banerjee, A. and Eckard, E. W. (1998). 'Are Mega-mergers Anticompetitive? Evidence from the First Great Merger Wave', Rand Journal of Economics, Vol. 29, pp. $803-827$.

Belleflamme, P. (2000). 'Stable Coalition Structures with Open Membership and Asymmetric Firms', Games and Economic Behavior, Vol. 30, pp. 1-21.

Bloch, F. (1995). 'Endogenous Structures of Associations in Oligopolies', Rand Journal of Economics, Vol. 26, pp. 537-556.

Bloch, F. (1996). 'Sequential Formation of Coalitions with Fixed Payoff Division', Games and Economic Behaviour, Vol. 14, pp. 90-123.

Bloch, F. (1997). 'Non Cooperative Models of Coalition Formation in Games with Spillovers', in C. Carraro and D. Siniscalco (eds), New Directions in the Economic Theory of the Environment, Cambridge, Cambridge University Press.

Bloch, F. (2002). 'Coalition and Networks in Industrial Organization', The Manchester School, Vol. 70, pp. 36-55.

Bloch, F. (2003). 'Coalition Formation in Games with Spillovers', in C. Carraro (ed.), The Endogenous Formation of Economic Coalitions, Fondazione Eni Enrico Mattei Series on Economics and the Environment, Cheltenham, UK and Northampton, MA, Elgar.

Bulow, J., Geneakoplos, J. and Klemperer P. (1985). 'Multimarket Oligopoly: Strategic Substitutes and Complements', Journal of Public Economics, Vol. 93, pp. 488-511.

Chander, P. and Tulkens, H. (1997). 'The Core of an Economy with Multilateral Externalities', International Journal of Game Theory, Vol. 26, pp. 379-401.

Cheung, F. K. (1992). 'Two Remarks on the Equilibrium Analysis of Horizontal Merger', Economics Letters, Vol. 40, pp. 119-123.

Clarke, R. (1983). 'Collusion and the Incentives for Information Sharing', Bell Journal of Economics, Vol. 14, pp. 383-394.

Currarini, S. and Feri, F., (2013). 'Information Sharing Networks in Linear Quadratic Games', mimeo. 
Currarini, S. and Marini, M. A. (2003). 'A Sequential Approach to the Characteristic Function and the Core in Games with Externalities', in M. Sertel and A. Kara (eds), Advances in Economic Design, Berlin, Springer Verlag.

Currarini, S. and Marini, M. A. (2004). 'A Conjectural Cooperative Equilibrium in Strategic Form Games', in C. Carraro and V. Fragnelli (eds), Game Practise and the Environment, Cheltenham, Edward Elgar.

Currarini, S. and Marini, M. A. (2006). 'Coalition Formation in Games without Synergies', International Game Theory Review, Vol. 8, No. 1, pp. 111-126.

d'Aspremont, C. and Gabszewicz, J. J. (1986). 'On the Stability of Collusion', in J. Stiglitz and G. F. Mathewson (eds), New Developments in the Analysis of Market Structure, Boston, MA, MIT Press.

d'Aspremont, C., Jaquemin, A., Gabszewicz, J. and Weymark, J. (1982). 'On the Stability of Dominant Cartels', Canadian Journal of Economics, Vol. 14, pp. 17-25.

Daughety, A. (1990). 'Beneficial Concentration', American Economic Review, Vol. 80, pp. 1231-1237.

Deneckere, R. and Davidson, C. (1985). 'Incentive to Form Coalitions with Bertrand Competition', Rand Journal of Economics, Vol. 16, pp. 473-486.

Donsimoni, M., Economides, N. and Polemarchakis, H. (1986). 'Stable Cartels', International Economic Review, Vol. 27, pp. 317-327.

Driessen, T., Dongshuang, H. and Lardon, A. (2011). 'Stackelberg Oligopoly TU-games: Characterization of the Core and 1-concavity of the Dual Game', Working Paper, July.

Ebina, T. and Shimizu, D. (2009). 'Sequential Mergers with Differing Differentiation Levels', Australian Economic Papers, Vol. 48, pp. 237-251.

Escrihuela-Villar, M. and Faulí-Oller, R. (2008). 'Mergers in Asymmetric Stackelberg Markets', Spanish Economic Review, Vol. 10, No. 4, pp. 279-288.

Farrell, J. and Shapiro, C. (1990). 'Horizontal Mergers: an Equilibrium Analysis', American Economic Review, Vol. 80, No. 1, pp. 107-126.

Faulí-Oller, R. (1997). 'On Merger Profitability in a Cournot Setting', Economics Letters, Vol. 54, pp. 75-79.

Federal Trade Commission (1999). 'Promoting Competition, Protecting Consumers: a Plain English Guide to Antitrust Laws', http://www.ftc.gov/tips-advice/ competition-guidance/guide-antitrust-laws

Fudenberg, D. and Tirole, J. (1991). Game Theory, Cambridge, MA, MIT Press.

Gal-or, E. (1985). 'Information Sharing in Oligopoly', Econometrica, Vol. 53, pp. 329-343.

Gonzalez-Maestre, M. and Lopez-Cunat, J. (2001). 'Delegation and Mergers in Oligopoly', International Journal of Industrial Organization, Vol. 19, No. 8, pp. $1263-1279$.

Hamilton, J. and Slutsky, S. (1990). 'Endogenous Timing in Duopoly Games: Stackelberg or Cournot Equilibria', Games and Economic Behavior, Vol. 2, pp. 29-46.

Hart, S. and Kurz, M. (1983). 'Endogenous Formation of Coalitions', Econometrica: Journal of the Econometric Society, Vol. 52, pp. 1047-1064.

Huck, S., Konrad, K. A. and Müller, W. (2001). 'Big Fish Eat Small Fish: on Merger in Stackelberg Markets', Economic Letters, Vol. 73, pp. 213-217.

Huck, S., Konrad, K. A. and Müller, W. (2005a). 'Merger without Cost Advantages', CESifo Working Paper Series 1461.

Huck, S., Konrad, K. A. and Müller, W. (2005b). 'Profitable Horizontal Mergers without Cost Advantages: the Role of Internal Organization, Information and Market Structure', Economica, Vol. 71, pp. 575-587. 
Ichiishi, T. (1983). 'A Social Coalitional Equilibrium Existence Lemma', Econometrica: Journal of the Econometric Society, Vol. 49, pp. 369-377.

Jaquemin, A. and Margareth, S. (1989). 'Cartels, Collusion and Horizontal Mergers', in R. Schmalensee and R. D. Willig (eds), Handbook of Industrial Organization, New York, Elsevier.

Kuhn, K. U. and Vives, X. (1995). Information Exchanges among Firms and their Impact on Competition, Luxemburg, Office for Official Publications for the European Community.

Lardon, A. (2012). 'The $\gamma$-core in Cournot Oligopoly TU-games with Capacity Constraints', Theory and Decision, Vol. 72, pp. 387-411.

Lekeas, P. (2013). 'Coalitional Beliefs in Cournot Oligopoly TU Games', International Game Theory Review, Vol. 15, pp. 1-21.

Li, L. (1985). 'Cournot Oligopoly with Information Sharing', Rand Journal of Economics, Vol. 16, pp. 521-536.

Malueg, D. and Tsutsui, S.O. (1996). 'Coalition Proof Information Exchanges', Journal of Economics, Vol. 63, pp. 259-278.

Marini, M. A. (2009). 'Games of Coalition and Network Formation: a Survey', in A. Naizmada, S. Stefani and A. Torriero (eds), Networks, Dynamics and Topology, London and Berlin, Springer-Verlag.

Marini, M. A., Petit, M. L. and Sestini, R. (2014). 'The Strategic Timing of R\&D Agreements', Economics of Innovation and New Technology, Vol. 23, pp. 274-303.

Markham, J. W. (1951). 'The Nature and Significance of Price Leadership', American Economic Review, Vol. 41, pp. 891-905.

von Neumann, J. and Morgenstern, O. (1944). Theory of Games and Economic Behaviour, Princeton, Princeton University Press.

Novshek, W. and Sonnenschein, H. (1982). 'Fulfilled Expectations Cournot Duopoly with Information Acquisition and Release', Bell Journal of Economics, Vol. 13, pp. 214-218.

Office of Fair Trading (1999). 'Merger Appraisal in Oligopolistic Markets', Economic Research Paper 19, November.

Owen, G. (1977). 'Values of Games with a Priori Unions', in R. Henn and O. Moeschlin (eds), Lecture Notes in Economics and Mathematical Systems, Essays in Honor of Oskar Morgenstern, Nueva York, Springer Verlag, pp. 76-88.

Perry, M. K. and Porter, R. H. (1985). 'Oligopoly and the Incentive for Horizontal Merger', American Economic Review, Vol. 75, No. 1, pp. 219-227.

Raith, M. (1996). 'A General Model of Information Sharing in Oligopoly', Journal of Economic Theory, Vol. 71, pp. 260-288.

Rajan, R. (1989). 'Endogenous Coalition Formation in Cooperative Oligopolies', International Economic Review, Vol. 30, pp. 863-876.

Ray, D. and Vohra, R. (1997). 'Equilibrium Binding Agreements', Journal of Economic Theory, Vol. 73, No. 1, pp. 30-78.

Ray, D. and Vohra, R. (1999). 'A Theory of Endogenous Coalition Structures', Games and Economic Behavior, Vol. 26, No. 2, pp. 286-336.

Salant, S. W., Switzer, S. and Reynolds, R. J. (1983). 'Losses from Horizontal Merger: the Effects of an Exogenous Change in Industry Structure on Cournot-Nash Equilibrium', Quarterly Journal of Economics, Vol. 98, No. 2, pp. 185-199.

Shaffer, S. (1995). 'Stable Cartels with a Cournot Fringe', Southern Journal of Economics, Vol. 61, pp. 744-754.

Shaked, A. (1986). 'A Comment', in J. Stiglitz and G. F. Mathewson (eds), New Developments in the Analysis of Murket Structure, Boston, MA, MIT Press.

Shenoy, P. P. (1979). 'On Coalition Formation: a Game Theoretical Approach', International Journal of Game Theory, Vol. 8, pp. 133-164. 
Thoron, S. (1998). 'Formation of a Coalition-proof Stable Cartel', Canadian Journal of Economics, Vol. 31, No. 1, pp. 63-76.

Thrall, R. and Lucas, W. (1963). ' $N$-person Games in Partition Function Form', Naval Research Logistics Quarterly, Vol. 10, pp. 281-298.

Vives, X. (1985). 'Duopoly Information Equilibrium: Cournot and Bertrand', Journal of Economic Theory, Vol. 34, pp. 71-94.

Watanabe, T. and Matsubayashi, N. (2013). 'Note on Stable Mergers in Markets with Asymmetric Substitutability', Economics Bulletin, Vol. 33, pp. 2024-2033.

Yi, S.-S. (1997). 'Stable Coalition Structure with Externalities', Games and Economic Behaviour, Vol. 20, pp. 201-237.

Yi, S.-S. (2003). 'The Endogenous Formation of Economic Coalitions: the Partition Function Approach', in C. Carraro (ed.), The Endogenous Formation of Economic Coalitions, Fondazione Eni Enrico Mattei Series on Economics and the Environment, Cheltenham, UK and Northampton, MA, Elgar.

Zhao, J. (1997). 'A Cooperative Analysis of Covert Collusion in Oligopolistic Industries', International Journal of Game Theory, Vol. 26, No. 2, pp. 249-266.

Zhao, J. (1999). 'A 3b2-core Existence Result and its Application to Oligopoly Markets', Games and Economic Behavior, Vol. 27, pp. 153-168.

Zhao, J. (2013). 'The Most Reasonable Solution for an Asymmetric Three-firm Oligopoly', mimeo, Saskatchewan, Canada, March 2013.

Ziss, S. (2001). 'Horizontal Mergers and Delegation', International Journal of Industrial Organization, Vol. 19, pp. 3-4, 471-492. 